North and South

Tunnel Portals

Both north and south tunnel entrances feature an operations building. These buildings run the tunnel's state-of-the-art lighting, traffic management and safety systems, house maintenance facilities, and each feature four distinctive yellow ventilation stacks.

Operations buildings

- Yellow ventilation stacks: $\mathbf{4 0}$ feet tall

- Ventilation stack diameter: 10 feet

- Ventilation stack weight: $\mathbf{3 0 , 0 0 0}$ pounds (built in Longview, Wash.)

- Ventilation fans: $\mathbf{5 0 0}$ horsepower, can each move 160,000 cubic feet of air per minute

The final SR 99 tunnel will be longer than the 1.7 mile section dug by Bertha. The tunnel is extended at both ends with "cut-and-cover" tunnels to connect the bored tunnel to surface lanes. The cut-and-cover method is just like it sounds: dig a trench, then build a floor, walls and a roof to cover the trench.

Cut-and-cover tunnel facts

- South portal cut-and-cover length: 1,000 feet

- North portal cut-and-cover length: $\mathbf{4 5 0}$ feet

- Depth of north portal cut-and-cover excavation: 85 feet

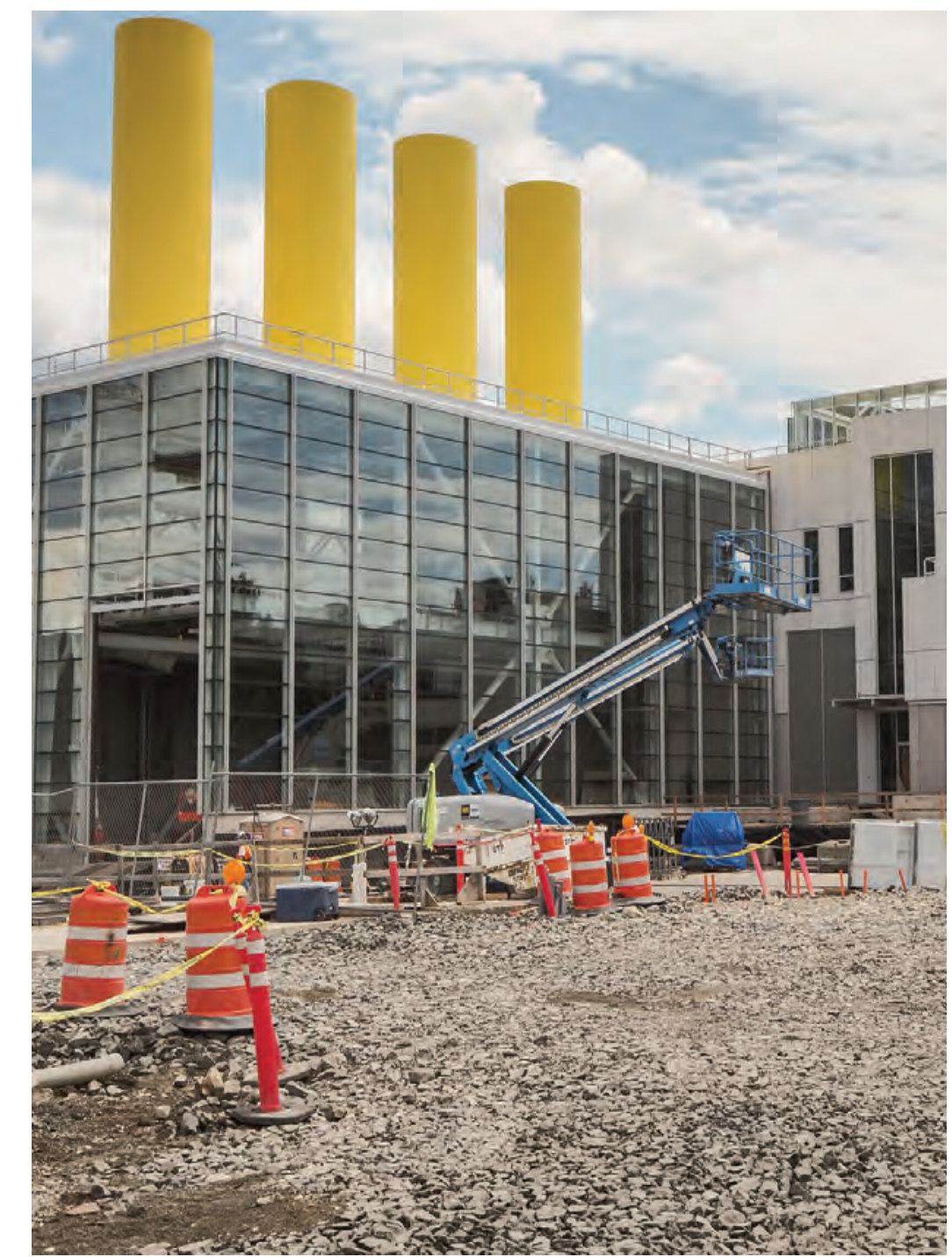

View of progress on the SR 99 tunnel's north portal operations building.

Send a letter to:

Waskn Way Viaduct Replacement Program

We

Seattle, WA 98104
Alaskan Way Viaduct R E P L A C E M $\underset{\text { PROGRAM }}{\mathrm{N} T}$

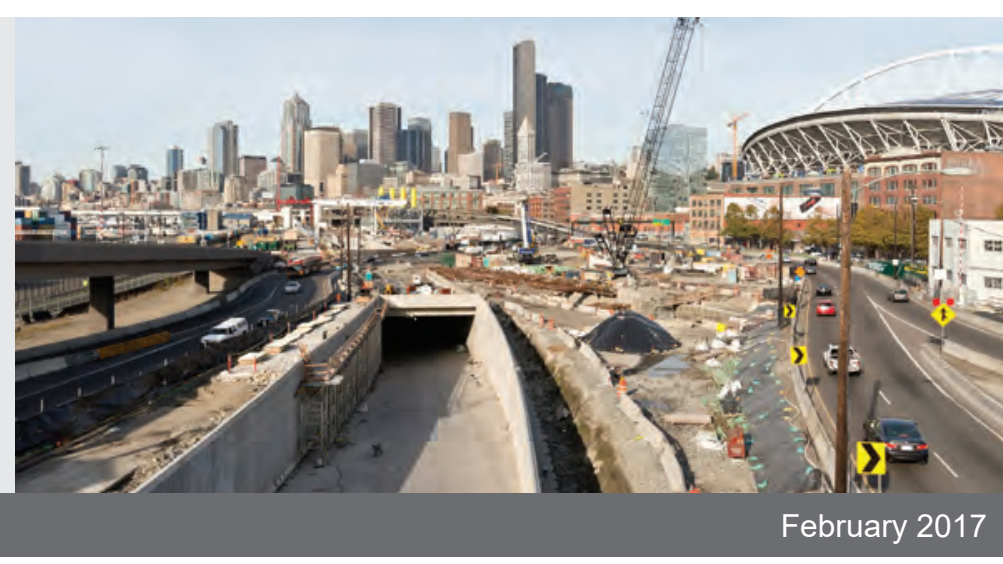

\section{Tunneling into the numbers}

The Washington State Department of Transportation is replacing Seattle's seismically vulnerable Alaskan Way Viaduct with a tunnel. Once open, the two-mile-long tunnel will carry two lanes of State Route 99 in each direction underneath downtown Seattle. Digging this remarkable tunnel is a record-breaking tunneling machine, nicknamed Bertha. Here are some numbers that highlight the scope of this megaproject.

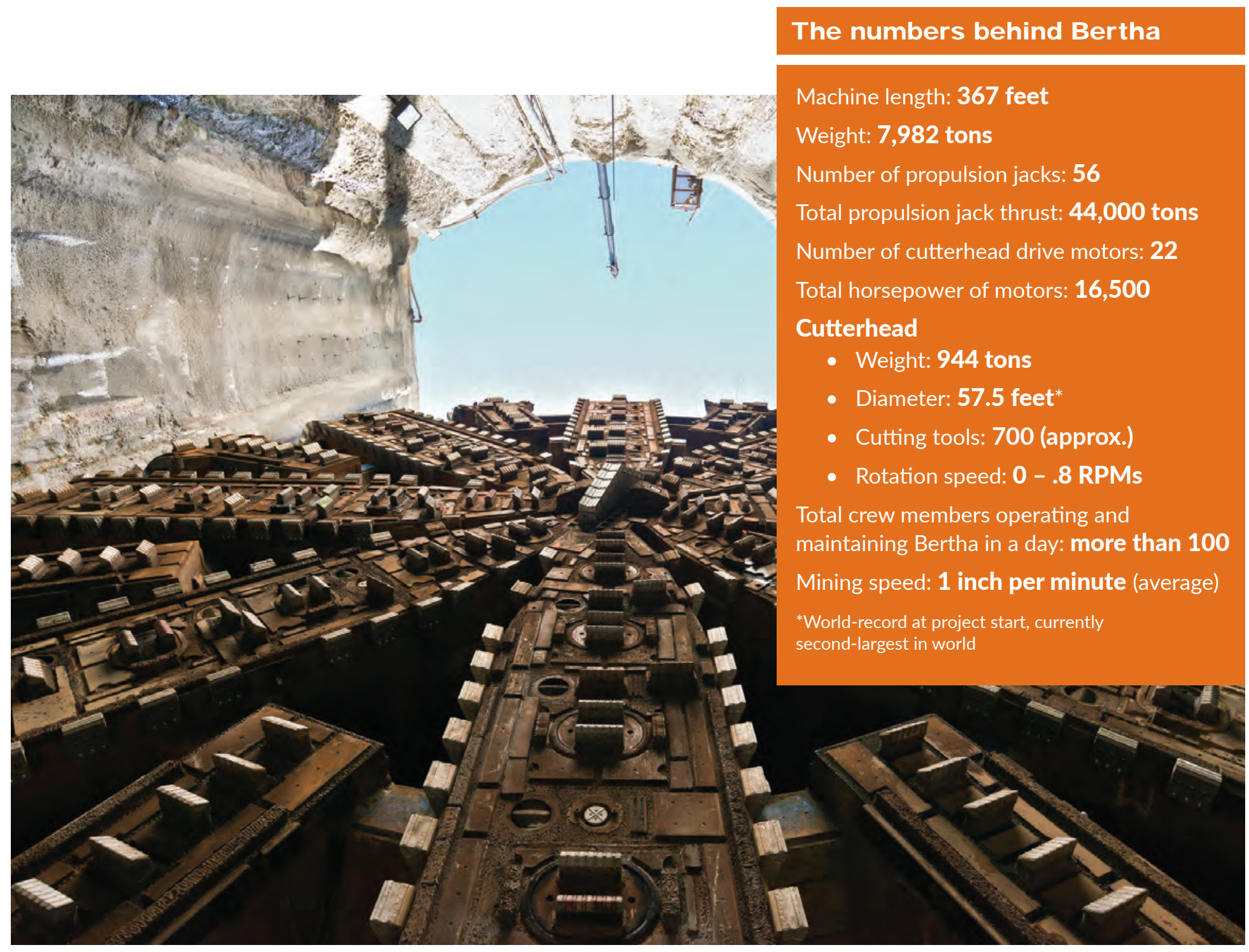

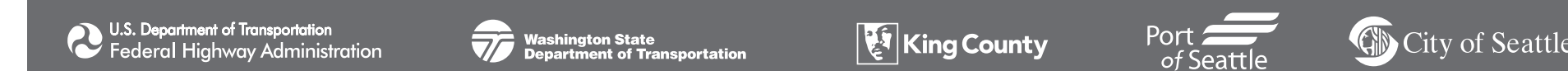

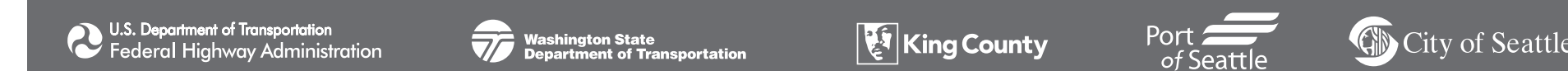

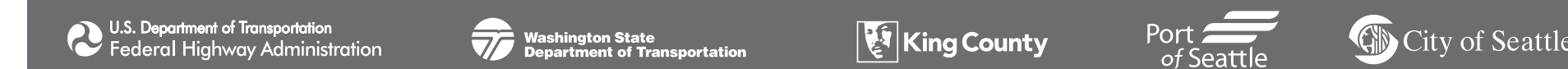

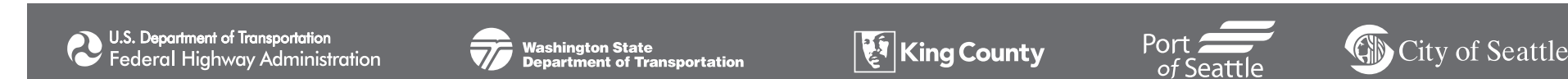

Americans with Disabilities Act \& Title Vl information

Americans with Disabilities Act (ADA) Information: This material can be made available in an alternate format by emailing the WSDOT Diversity/ADA Affairs team at wsdotada@wsdot.wa.gov or by calling toll free,

Title VI: It is the Washington State Department of Transportation's (WSDOT) policy to assure that no person shall, on the grounds of race, color, national origin or sex, as provided by Title VI of the Civil Rights Act of 1964, be excluded from participation in, be denied the benefts of, or be otherwise discriminated against under any of its federally funded programs and activities. Any person who belleves mist
her Title VI protection has been violated, may file a complaint with WSDOT's Office of Equal Opportunity (OEO). For additional information regarding Title $\mathrm{VI}$ complaint procedures and/or information regarding our non-discrimination obligations, please contact OEO's Title VI

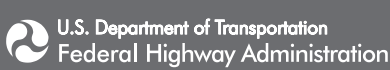

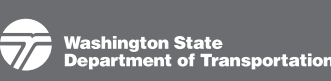

[6] King County

Port ${ }_{\text {of Seattle }}$ City of Seattle 
- Length: 9,270 feet (1.7 miles)

- Max depth: 215 feet $^{*}$

- Wall thickness: 2 feet

- Outside diameter: 56 feet

- Number of tunnel rings: 1,426

*Ground surface to crown of tunnel machine, near First Avenue and Virginia Stree

Bertha digs the tunnel by chipping, grinding and cutting away the ground with her cutterhead. The soil is mixed with conditioners to give it a toothpaste-like consistency, and then carried by a corkscrew-like conveyor toward the back of the machine. From there, a conveyor belt carries it out of the tunnel to a waiting barge.

Soil stats

- Types of soil along tunnel route: 8

- Amount of soil excavated per tunnel ring: about 550 cubic yards

- Number of barges used to haul soil: 3

- Amount of soil carried per barge: about 2,200 cubic yards

- Dump truck equilavent of one barge: $\mathbf{1 6 0}$ trucks

Bertha will remove 850,000 cubic yards of dirt from the ground during SR 99 tunnel mining

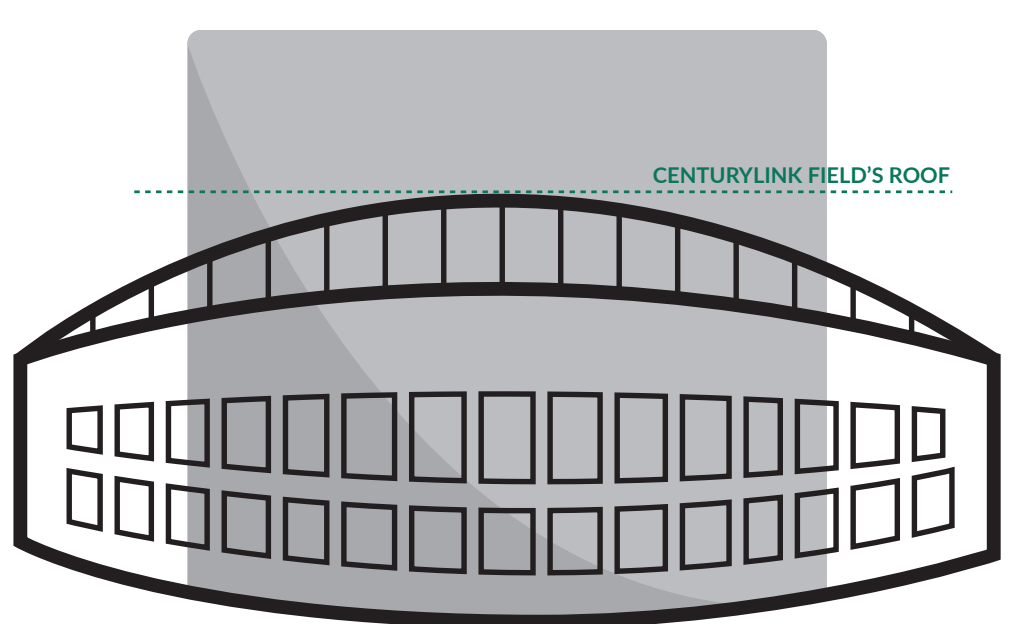

Piling the dirt on the football field in CenturyLink Field would create tower of dirt that would overtop the stadium by 100 feet
Width of tunnel rings: 6.5 feet

Tunnel ring weight: 172 tons cubic yards

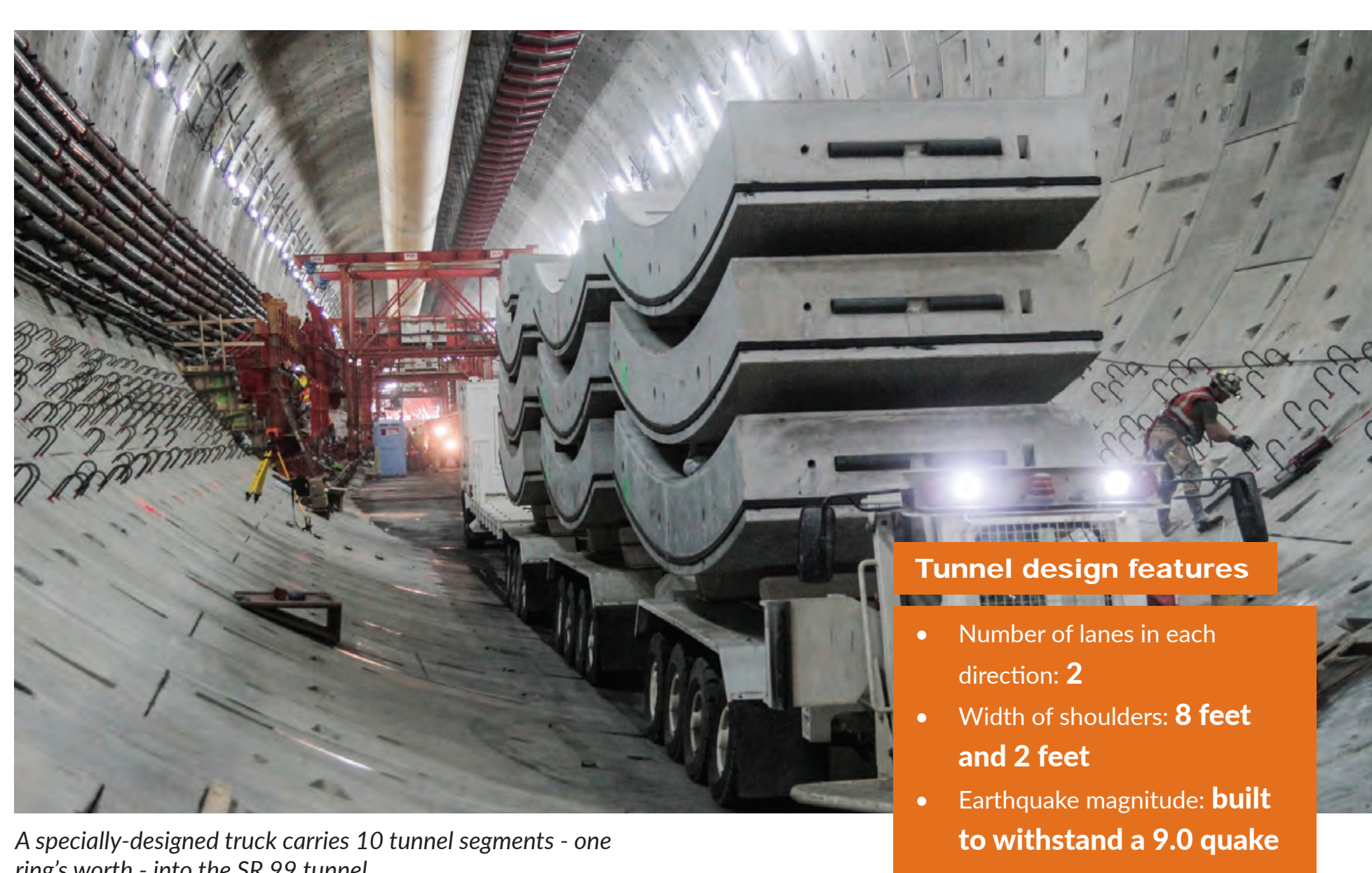

ring's worth - into the SR 99 tunnel.

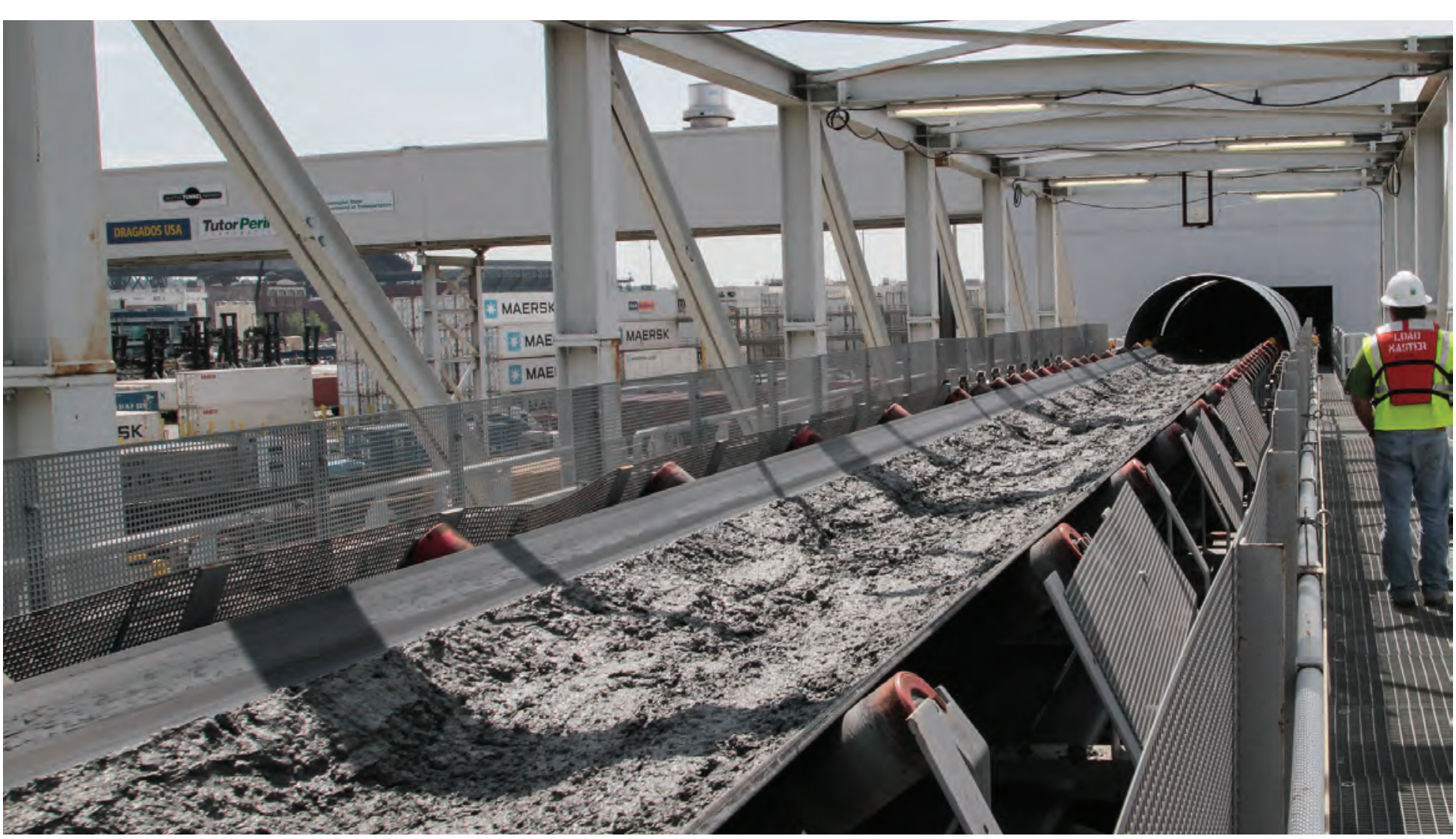

Conveyor carries spoils (tunnel soil) to the barge for disposal. 